The BDJ News section accepts items that include general news, latest research and diary events that interest our readers. Press releases or articles may be edited, and should include a colour photograph if possible. Please direct your correspondence to the News Editor, Arveen Bajaj at the BDJ, 64 Wimpole Street WIG 8YS or by email to bdj@bda.org

\section{Counting up your CPD hours}

The GDC is to post Continuing Professional Development (CPD) declaration forms to over 25,000 dentists in March as part of its mandatory CPD scheme. The form, which will be sent to all dentists who were first registered on or after 1 January 1980, asks how much verifiable and general CPD each dentist carried out in 2003.

The information on the form, which needs to be returned to the Council by the end of the month, will be added to the computer record of each dentist and the GDC will keep a tally over the dentist's 5year cycle. At the end of the 5-year CPD cycle, anyone who has not met the total of 250 hours could face erasure from the register.

The GDC also expects dentists to keep up to date even when not registered. Any dentist applying to return to the register after a break of 12 months or more will now have to prove they were complying with the CPD scheme during that time.

If for example a dentist was working abroad for a number of years or taking a career break, they would need to provide evidence that they had kept up to date by attending lectures, demonstrations or training events, to get back on to the register. The scheme requires dentists to do and record 250 hours of CPD over a fiveyear cycle. At least 75 of these 250 hours must be spent undertaking verifiable CPD. The remainder can be general CPD.

Those with any questions about the scheme can contact the GDC registration team on 02078873800 or e-mail gdcregistration@gdc-uk.org.

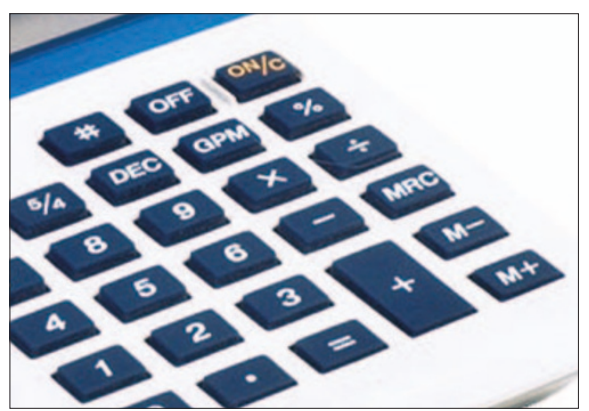

\section{New Cuban appointment}

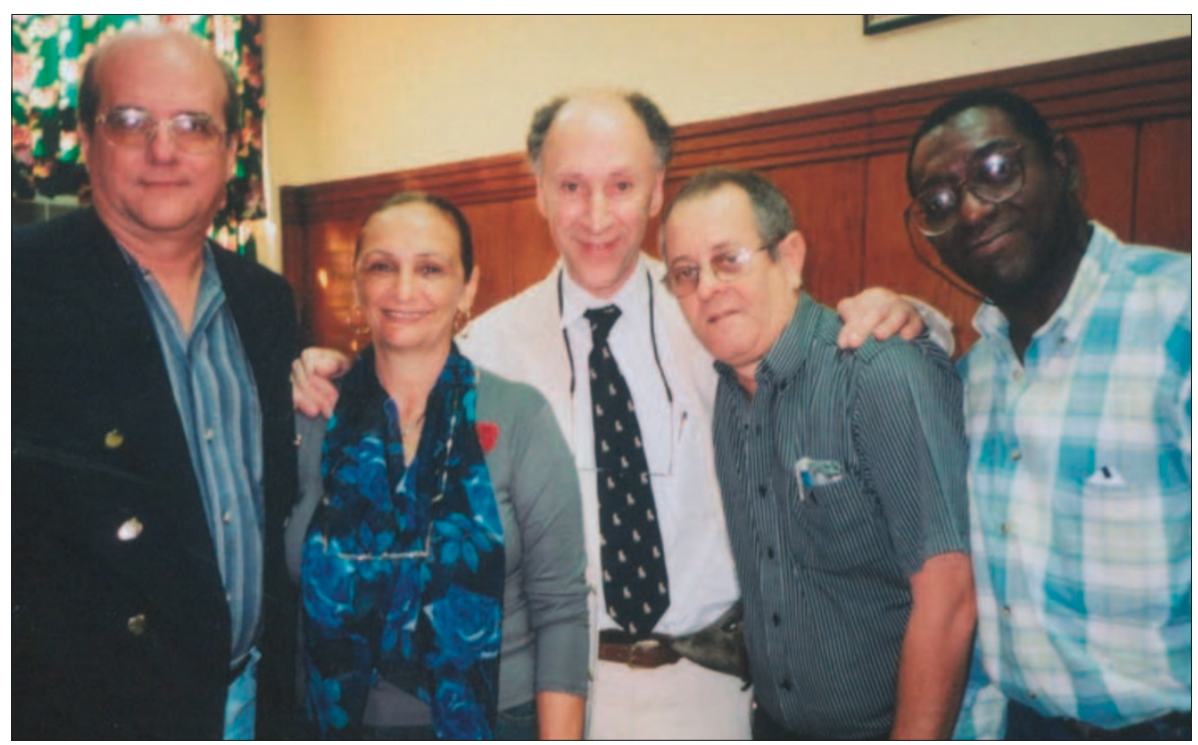

The University of Havana in Cuba has appointed its first British visiting Professor, only the third such appointment since the foundation of the Faculty over 100 years ago. Dr Howard Stean was appointed visiting Professor in restorative dentistry following a meeting of the Rector, Dean and members of the board. The appointment will be personally ratified by Havana's Minister of Health. (Pictured above Dr Stean (centre) with members of the board of the Dental Faculty at Havana).

\section{Dental caries a global health problem}

An estimated five billion people worldwide have experienced dental caries, according to the findings of the World Oral Health Report, released by the World Health Organisation (WHO).

It announced that oral diseases such as dental caries, periodontitis and oral and pharyngeal cancers were a global health problem in both industrialized and increasingly in developing countries, especially amongst poorer communities.

The report stated that while there was a perception that dental caries is no longer a problem in the developed world, it affects 60-90\% of schoolchildren and the vast majority of adults. It added that dental caries is also the most prevalent oral disease in several Asian and Latin American countries.

WHO warned that the same problem appeared to be less severe in most African countries, but with The WHO headquarters in Geneva changing living conditions, dental caries is expected

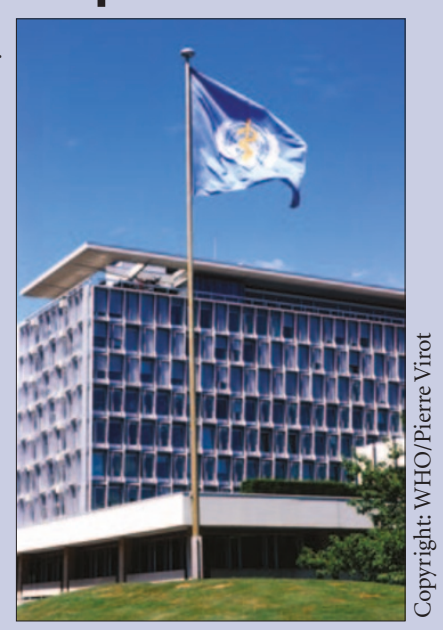
to increase in many developing countries in Africa, growing consumption of sugars and inadequate exposure to fluorides. WHO's Global Oral Health Programme is set out in the report and in addition to addressing oral hygiene practices, sugar consumption, lack of calcium and micronutrients and tobacco use, key elements include addressing poor living conditions and low education levels as well as lack of traditions supporting oral health. 


\section{DIARY}

March 2004

ASLMS Annual Meeting

Date: 31.03.04-04.04.04

Venue: Dallas, Texas

Contact: Jim Elliott

Tel: 7158459283

Email: jim@kinzieandgreen.com

www.asIms.org

April 2004

Avoiding failures and maximising success in restorative dentistry

Date: 02.04.04

Venue: Tunbridge Wells

Contact: Elisabeth Jarrett

Tel: +44 (0)1892 654384

Email: elisabeth.jarrett@btinternet.com

1st European Conference on Preventive \& Minimally Invasive Dentistry

Date: 16-17.04.04

Venue: Copenhagen

Contact: Conference office

Tel: +45 45937028

Fax: +45 45937029

Email:pc@quintessence.dk

May 2004

British Dental Conference and Exhibition

Date: 06-08.05.04

Contact: Delegate Management Services

Venue: Bournemouth International

Centre (BIC)

Tel: 08701666625 or + 44 (0) 1252

771425 (from overseas)

Fax: 08705228890 or + 44 (0) 1252

771790 (from overseas)

www.bda-events.org
First aid tooth kit launched

A group of dentists in MidUlster launched a free First Aid Kit for Tooth Injuries for all those in their area who lead sports activities and professionals who may encounter dental trauma.

The kit was produced to help people deal with tooth injury and prevent the distress of permanent tooth loss as many are unaware that a large percentage of knocked out adult teeth can be re-attached if the correct after-care is provided.

Funded by the Mid-Ulster Local Health and Social Care Group, a committee of the Northern Health and Social Services Board, the kit has a container for a tooth or tooth parts, a sterile pack, gloves, some saline and step-by-step instructions as well as an emergency out of hours dental telephone number.

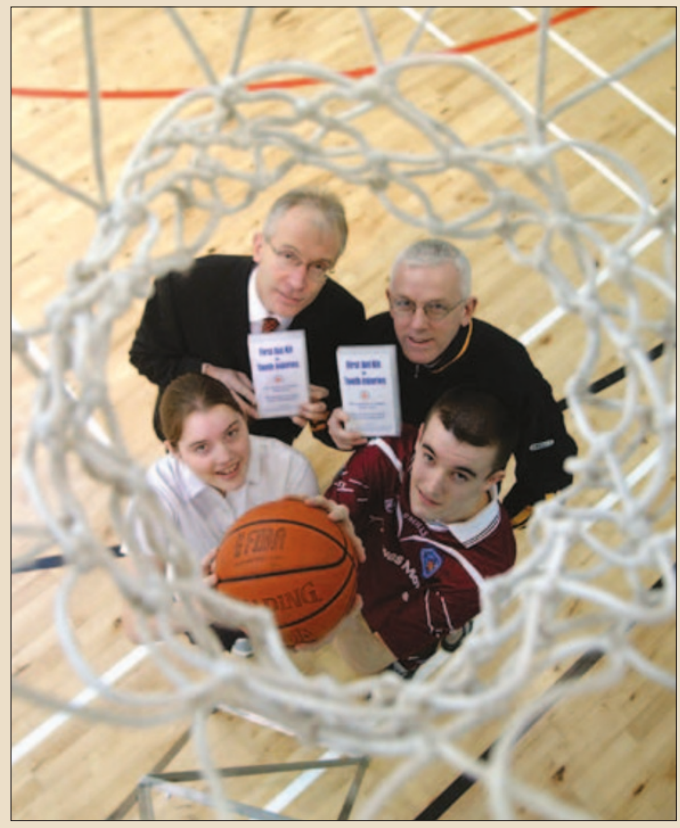

Pictured with the kit are Laurence O'Kane, Chairman of the Mid-Ulster Local Health and Social Care Group (back row left), Philip Kerr, a teacher at St Puis X College Magherafelt (back row right), and pupils Sinead Barker and James Rafferty.

\section{New appointment at St Andrews}

Gerry Humphris was inducted as Chair of Health Psychology at the University of St Andrews recently.

Based at the Bute Medical School, he will be furthering his research on the psychological aspects of oral health, particularly oral cancer.

He will also be contributing to the teaching of communication and behavioural science to undergraduate clinical training.

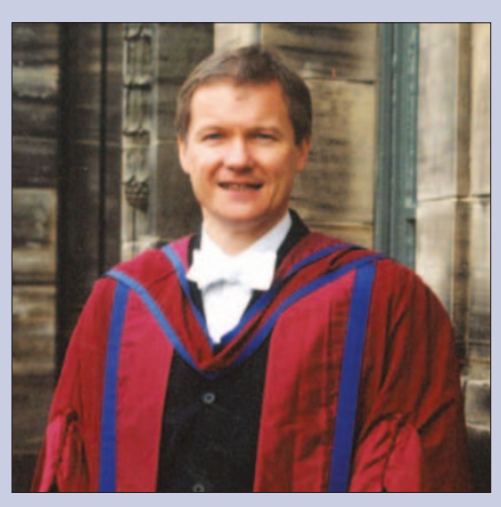




\section{Investor in People success}

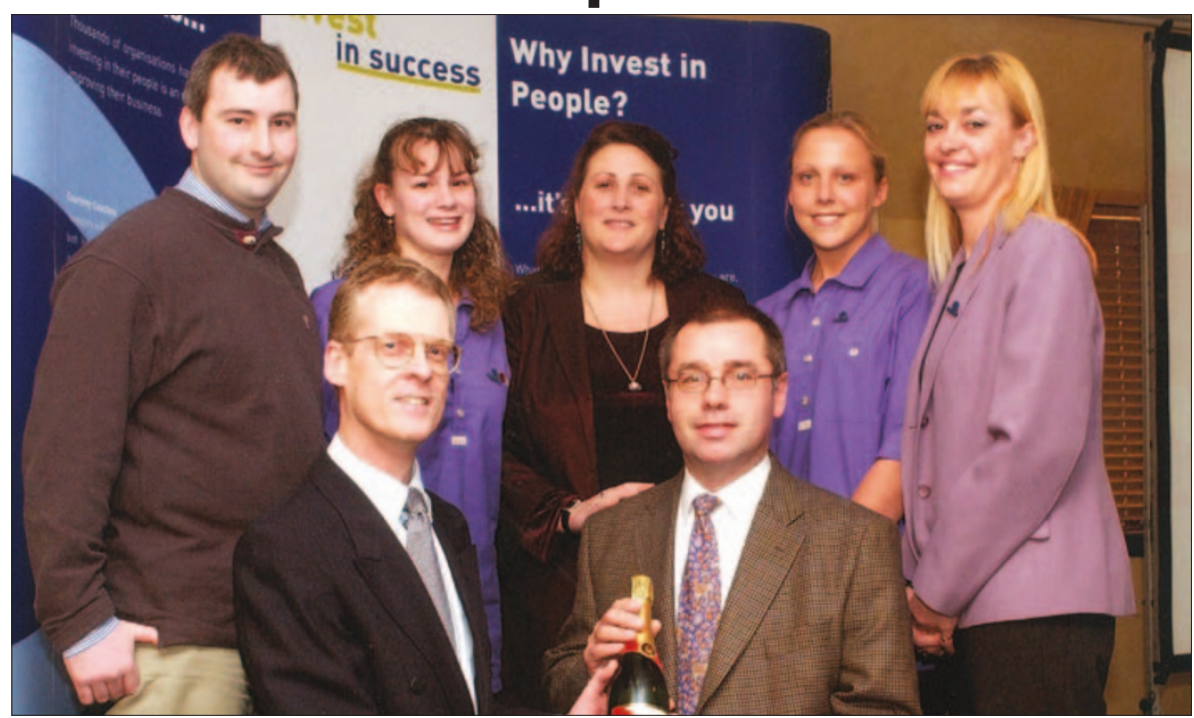

Old College Dental Surgery in Chippenham, Wiltshire were recently recognised as an Investor in People. The team received a bottle of champagne from Clive Bingham, chief executive of Investors in People at a ceremony in Newbury. Above, seated left to right, Clive Bingham and Paul Copson. Standing left to right, Ross Wilson, Rachel Watchorn, Beverly Copson, Becky King and Jayne Wickham.

\section{Lucky prize draw winner picked}

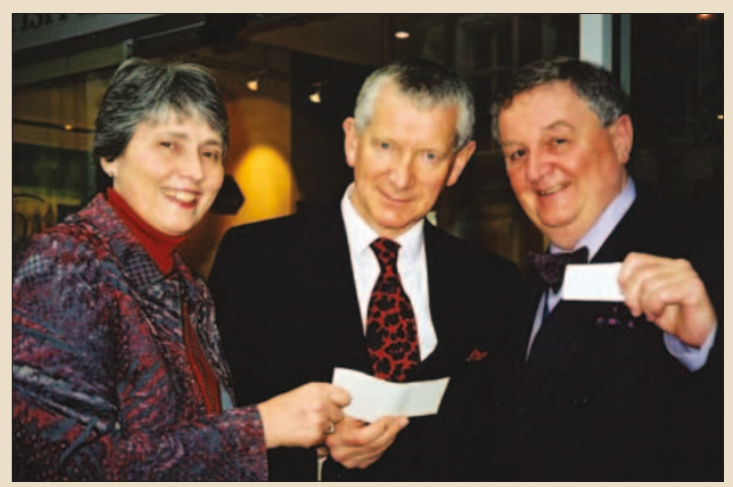

Left to right, Mavis Phipps, winner Mr Wakeham and Ralph Davies
Mr J. Wakeham of London was the lucky winner of the $£ 6,000$ first prize in the Dentists' Benevolent Fund's Christmas Draw.

The winning ticket was picked from hundreds by Ralph Davies, Chairman of the Representative Body at their meeting in January.

The draw raised $£ 31,600$ in 2003 and a cheque for this amount was present to Ian McIntyre BDA President and Benevolent Fund Treasurer.

\section{New archive room opened}

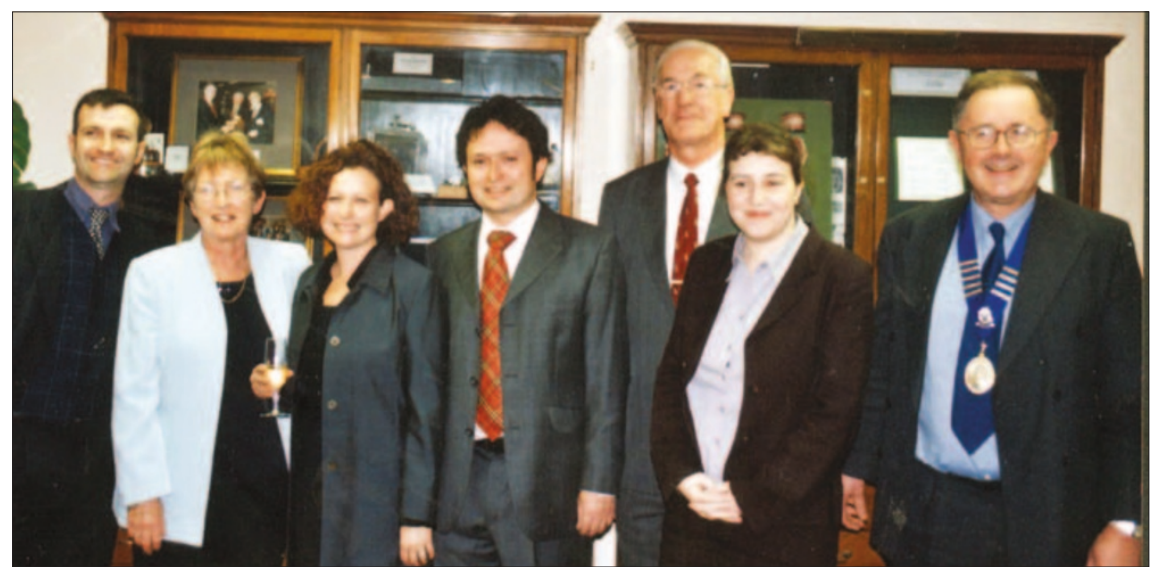

A new room housing the archive of the British Orthodontic Society (BOS) has been officially opened and dedicated to the memory of David DiBiase, the first chairman of the society at its formation in 1994. The plaque bearing his name was unveiled by his widow Moyra DiBiase and by John Williams, the current president of the BOS. The archive has been established at the BOS headquarters in London's Gray's Inn Road. (Pictured left to right, James, Moyra, Judy and Andrew DiBiase (the family of David DiBiase) with Professor Jim Moss, Helen Travess and John Williams). 